\title{
Plasticity of Process-Bearing Glial Cell Cultures from Neonatal Rat Cerebral Cortical Tissue
}

\author{
Christine A. Ingraham ${ }^{1}$ and Ken D. McCarthy ${ }^{1,2}$ \\ Neurobiology Curriculum and 2Department of Pharmacology, University of North Carolina at Chapel Hill, Chapel Hill, \\ North Carolina 27514
}

The factors and cellular interactions that influence the commitment of cells to specific neural lineages are not well understood. We have used cultured non-neuronal processbearing (PB) cells from neonatal rat cerebral cortices as a model to assess the influence of various culture conditions on the determination of cells as either astroglia or oligodendroglia.

Increasing postseparation plating density was significantly associated $(p<0.001)$ with decreasing percentages of glial fibrillary acidic protein $(G F A P+)$ cells, increasing percentages of galactocerebroside $(G C+)$ cells, and increasing percentages of nonstained cells. As the fetal calf serum content of growth medium was increased, the percentage of GFAP + cells increased, and as the serum content was decreased, the percentage of $\mathrm{GC}+$ cells increased. Evidence of minimal cell proliferation and the observation of PB cells that coexpressed GFAP and GC supported the conclusion that PB cells switched their phenotypic expression from GFAP+ in serum to GC+ in serum-free medium. PB cells exhibited plasticity in their phenotypic expression as cells grown for $9 d$ in serum-free medium were still responsive to the effects of serum, while cells grown for $6 \mathrm{~d}$ in serum were refractory to serum withdrawal.

This research has demonstrated the plasticity of PB cells separated from polygonal astroglia as they expressed GFAP In the presence of serum and GC in serum-free medium.

Neuroepithelial cells of the neural tube give rise to the astroglia and oligodendroglia of the CNS (Jacobson, 1978). It is not clear when the oligodendroglial and astroglial lineages diverge or what factors may influence the determination of these cell types. As it is difficult to determine factors that may influence cell determination in vivo, a number of in vitro model systems have been developed to study glial cell development. One such system that has been widely uscd is the McCarthy and dcVcllis procedure (1980), in which glial cells can be isolated from the cerebral cortices of neonatal rats. The process-bearing (PB) cells derived by this culture method were originally described as oligodendroglia. This characterization was made on the basis of EM morphological analysis and biochemical assays. When these cul-

\footnotetext{
Received Aug. 18, 1987; revised May 24, 1988; accepted May 27, 1988.

This work was supported hy IJSPHS Grants 21696 and 20212. The secretarial assistance of Margaret Tapp is gratefully acknowledged.

Correspondence should be addressed to Dr. Ken D. McCarthy, Department of Pharmacology, School of Medicine, CB \#7365, 1138 F.L.O.B., University of North Carolina, Chapel Hill, NC 27599.

Copyright(C) 1989 Society for Neuroscience 0270-6474/89/010063-07\$02.00/0
}

tures were examined subsequently using immunocytochemistry with cell-specific markers, we (Ingraham and McCarthy, 1984) and others (Poduslo et al., 1984; Zeller et al, 1985; DuboisDalcq et al., 1986; Goldman et al., 1986) found that these cultures contained not only oligndendroglia, but also astroglia, and cells that did not express markers of either glial phenotype. Oligodendroglia and astroglia were defined using the cell-specific markers galactocerebroside (GC) and glial fibrillary acidic protein (GFAP) (Norton and Autilio, 1966; Bignami et al., 1972; Raff et al., 1978).

We hypothesized that at least 2 situations could have led to this discrepancy between the 2 characterizations. First, there could have been subtle changes in the culture procedure at steps not specified in the original preparation that resulted in the inclusion of GFAP + and nonstained cells in the PB cell population. Another possibility was that the cells being isolated were in a developmental period of plasticity so that they could develop into either oligodendroglia or astroglia depending on the culture conditions. This typc of cell population would be analogous to that described by Raff et al. (1983) in cultures of rat optic nerve. Experiments were designed to distinguish between these 2 possibilities.

Our data support the conclusion that PB cells obtained from cerebral cortical cultures were cells whose determination could be influenced by culture conditions, particularly the composition of their growth medium. We also observed that there was a limited time period during which $\mathrm{PB}$ cell determination was responsive to the effects of serum withdrawal.

\section{Materials and Methods}

Preparation of cerebral cortical primary cell cultures. Cultures were prepared essentially as described by McCarthy and deVellis (1978). Cells were plated into T-flasks $\left(75 \mathrm{~cm}^{2}\right.$ area $)$ at approximately $1.8 \times 10^{5}$ cells/ $\mathrm{cm}^{2}$ unless otherwise specified. Media components were purchased from Gibco (Grand Island, NY) and Sigma (St. Louis). Fetal calf serum was purchased from Irvine Scientific (Santa Ana, CA).

Separation of $P B$ cells from cortical cultures. The method used was that of McCarthy and deVellis (1980). Shaken-off PB cells were plated onto glass coverslips coated with poly(D-lysine), $10 \mu \mathrm{g} / \mathrm{ml}$, in $35 \mathrm{~mm}$ dishes at a density of approximately $8 \times 10^{4} \mathrm{cells} / \mathrm{cm}^{2}$ unless otherwise specified. In most cxpcriments, cells werc maintaincd in BME supplcmented with $10 \%$ fetal calf serum. In certain experiments, cells were grown in BME with various percentages of fetal calf serum or in defined medium, either N2 (Bottenstein and Sato, 1979) or ODM (oligodendrocyte defined medium; Saneto and deVellis, 1985). In these cases, cell suspensions in BME with $10 \%$ fetal calf serum were plated onto coverslips; the cells were allowed to attach for $18 \mathrm{hr}$, and were then rinsed 3 times with unsupplemented medium. These cells were then fed with the appropriate medium as specified by the experimental protocol. Cells were grown for $7 \mathrm{~d}$, unless indicated otherwise, and were then examined by double-label indirect immunofluorescence microscopy. 
Antibodies. Antiserum to GFAP (rabbit immunoglobulins to human or bovine GFAP; Accurate Chemicals, Westbury, NY) was used as a marker for astroglia. The specificity of the antiserum was confirmed by 2 assays. First, proteins from PB cells were separated by 2 -dimensional gel electrophoresis according to the method of O'Farrell (1975) and were diffusion-blotted and immunostained according to the procedure of McCarthy et al. (1985). The antiserum was specific with regard to its reaction to GFAP (identified by its molecular weight and isoelectric point) as compared with other proteins of PB cells (Meyer et al., 1986). Second, cellular specificity could be demonstrated by the absence of immunoreactivity with nonastroglial cell types such as fibronectin-positive cells and neurofilament-positive cells. Mouse monoclonal antibody to GC (generously supplied by Dr. Barbara Ranscht) was used to identify oligodendroglia. This monoclonal antibody has been well-characterized (Ranscht et al., 1982). Fluorescein-conjugated goat anti-mouse IgG and rhodamine-conjugated goat anti-rabbit $\operatorname{IgG}\left[\mathrm{F}\left(\mathrm{ab}^{\prime}\right)_{2}\right]$ were purchased from Cappel/Cooper Biomedical (West Chester, PA).

Immunocytochemistry. Cclls grown on covcrslips werc staincd using a double-label indirect immunofluorescence protocol (Trimmer et al., 1984), except that staining with the anti-GC antibody was carried out on live cells. Controls for specificity included observation of the immunocytochemical reaction when primary antibodies were omitted, and when ascites fluid $(1: 100)$ and normal rabbit serum were used in place of the primary antibodies.

${ }^{3} H$-thymidine autoradiography. PB cells grown in either BME with $20 \%$ fetal calf serum or in N2 defined medium were labeled for $4 \mathrm{hr}$ with $3 \times 10^{-8} \mathrm{Ci} / \mathrm{ml}$ of methyl- ${ }^{-3} \mathrm{H}$-thymidine (specific activity, $72 \mathrm{Ci}$ / mmol; ICN, Irvine, CA) on day 2, 5, or 9 after separation of PB cells from polygonal astroglia. This level has been reported to have minimal effects on oligodendroglial cell death due to radiosensitivity (Hirayama et al., 1984). Some cultures were stained immediately after the $4 \mathrm{hr}$ pulse. Sister cultures were rinsed to remove unincorporated radioactivity and were grown until day 9, when they were stained. Following the staining, coverslips were processed for autoradiography. Cells with 10 or more grains over the nucleus were considered labeled.

Data collection. Cells stained using the immunocytochemical protocol detailed above or treated for combined immunocytochemistry and autoradiography were examined. In most experiments, cells on 15-45 nonoverlapping sequential fields/coverslip with 3 coverslips/treatment were visualized using a $63 \times$ oil-immersion objective and were counted. The total number of cells/field was determined using phase-contrast optics, and subsequently, the numbers of GC+, GFAP+, double-stained, and nonstained cells were determined using fluorescein and rhodamine optics. In ${ }^{3} \mathrm{H}$-thymidine autoradiographic experiments, the number of radiolabeled cells in each of these immunocytochemically defined categories was assessed.

\section{Results}

Effects of variation in the size and piece of cerebral cortex used in the culture preparation on the composition of the PB cell population

Neuroanatomical studies have shown that there is microheterogeneity in the cell types that are present in several brain regions, including the cerebral cortex. The size and piece of the cercbral cortex to be cultured was not specified by McCarthy and deVellis (1980). We observed that there was considerable variability in the piece of tissue that was cultured and the yield of PB cells obtained by different investigators, and we asked if differences in the piece of tissue used in the preparation could influence the yield of PB cells and the composition of cultures as determined by immunocytochemical staining. The cerebral cortex was folded out from the midline, and either the outer 1 $\mathrm{mm}$ or the outer $2 \mathrm{~mm}$ of tissue was removed for subsequent culture. PB cells were prepared and stained. Two experiments were carried out; 5013 cells from 5 coverslips were assessed for the $1 \mathrm{~mm}$ values, and 5465 cells from 5 coverslips were counted for the $2 \mathrm{~mm}$ values.

There were no significant differences in the percentages of $\mathrm{GC}+, \mathrm{GFAP}+$, or nonstained cells between the 1 and $2 \mathrm{~mm}$ cortex cultures. [Data were transformed using an arcsine trans- formation and were compared using unweighted $t$ tests (Cohen, 1969).] The cultures prepared from the $2 \mathrm{~mm}$ pieces of tissues yielded considerably more PB cells per animal than did those prepared from $1 \mathrm{~mm}$ pieces of tissue. In one experiment, cultures prepared from $2 \mathrm{~mm}$ pieces of tissue from 6 animals yielded approximately the same number $\left(3 \times 10^{6}\right)$ of $\mathrm{PB}$ cells as did $\mathrm{l}$ $\mathrm{mm}$ pieces from 24 animals.

\section{Effects of variations in plating densities of the initial cell suspension on the yield and composition of the PB cell population}

We addressed the possibility that the plating density of the initial cell suspension could influence the composition of the PB cells that were ultimately harvested from the cultures. There was considerable variation in the appearance of confluent cultures derived from a single cell suspension that was plated at initial plating densities that ranged from $7.2 \times 10^{5}$ to $4.5 \times 10^{4}$ viable cells $/ \mathrm{cm}^{2}$. At the highest density, there were numerous PB cells, which were often so dense as to almost obscure the bed layer polygonal astroglial cells. At early times in high-density cultures, we occasionally observed clumps of cells that extended neuritelike processes. These cells disappeared with time in culture, and the phase-bright cells that were present in confluent high-density cultures were probably remnants of dying cells. As the initial plating density was decreased, the number of PB cells found in these cultures also decreased. At the lowest density examined, $4.5 \times 10^{4} \mathrm{cells} / \mathrm{cm}^{2}$, there were no PB cells present on top of the bed layer of polygonal cells. At even lower plating densities, there was a tendency for the cultures to become overgrown by fibroblasts (data not shown).

There was no evidence of a consistent relationship between the initial plating density and the expression of either GFAP or GC hy the resultant PB cell population (Fig. 1). There was considerable variability among different culture preparations in the percentages of PB cells that expressed each marker or that were nonstained.

Effects of variations in the postseparation plating density of $P B$ cells on their expression of glial markers

PB cells plated at different postseparation densities and grown for $7 \mathrm{~d}$ were assessed as GFAP+, GC+, or nonstained (Fig. 2). Data were combined from 4 experiments and separate linear regressions were fit for the percentage of GFAP + on the postseparation density, for the percentage of GC+ cells on the postseparation density, and for the percentage of nonstained cells on the postseparation density. Increasing postseparation density was found to be associated $(p<0.001)$ with decreasing percentages of GFAP + cells, with increasing percentages of GC+ cells, and with increasing percentages of nonstained cells. At very low postseparation densities, only GFAP + PB cells were seen. As cell density became high, there may have been a tendency to be conservative in assessing whether cells were stained as it became difficult to identify cell processes clearly.

\section{Effects of variations in growth medium on the PB cell population}

We examined the effects of different culture media on the cellular morphology and the expression of immunocytochemical markers by PB cells. PB cell cultures were prepared as described. One day after separation, cultures were rinsed 3 times with unsupplemented medium, and test medium was placed on the cells. Culture medium was changed every $3 \mathrm{~d}$, and cultures were stained 

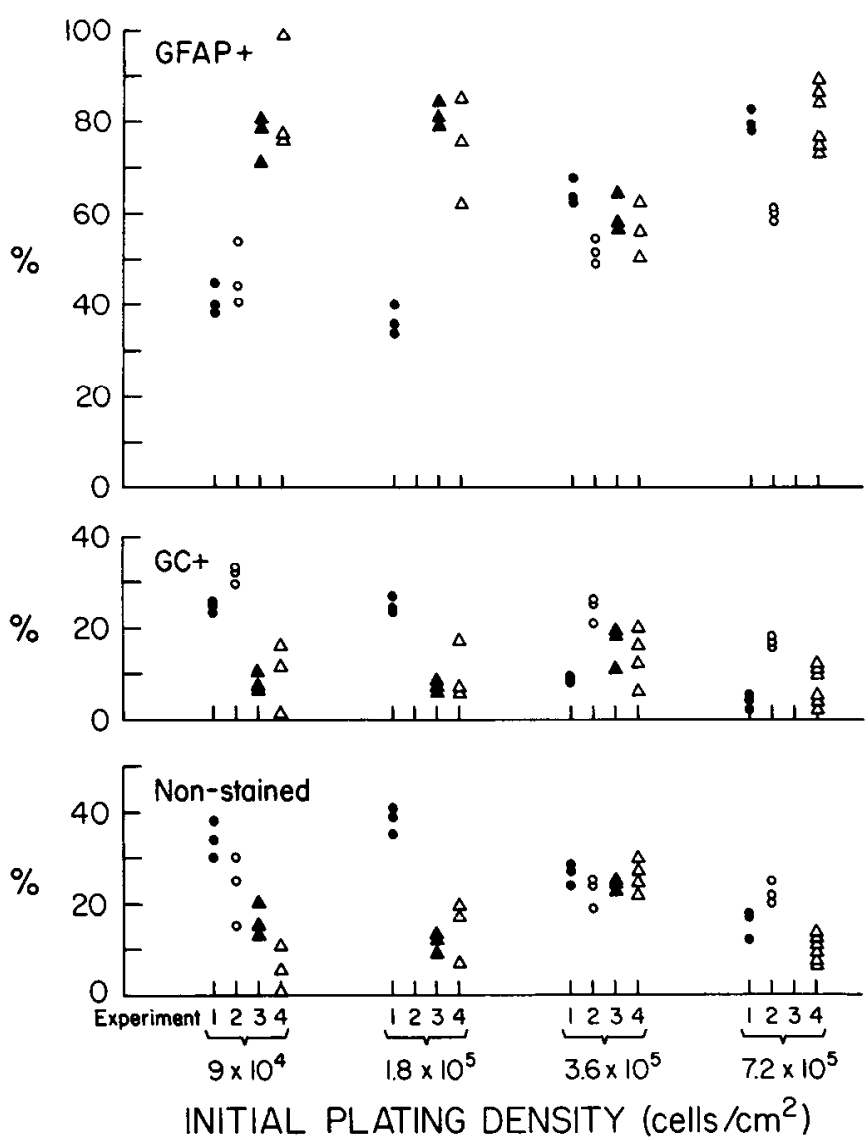

Figure 1. Quantitation of immunocytochemically identified PB cells derived from cultures plated at initial plating densities from $9 \times 10^{4}-$ $7.2 \times 10^{5} \mathrm{cells} / \mathrm{cm}^{2}$. Data shown indicate percentages of GFAP+, GC+, and nonstained PB cells from 4 experiments, each designated by a different symbol. Each point represents a value from a single coverslip on which at least 300 cells were counted.

6-7 d after test medium had been applied. The media tested included Eagle's basal medium with Earle's balanced salts containing $0.1 \%$ glutamine, $0.6 \%$ glucose, $50 \mathrm{IU} / \mathrm{ml}$ penicillin, and $50 \mu \mathrm{g} / \mathrm{ml}$ streptomycin sulfate supplemented with either 20,10 , 5 , or $2 \%$ fetal calf serum (BME- $20 \%$, BME- $10 \%$, BME- $5 \%$, BME$2 \%$ ). We also analyzed the effects of growth in 2 defined media, N2 (Bottenstein and Sato, 1979) and ODM (Saneto and deVellis, $1985)$ on the PB cells.

$\mathrm{PB}$ cells grown for $7 \mathrm{~d}$ in culture medium supplemented with either 20,10 , or $5 \%$ fetal calf serum often had numerous finc stellate processes and were typically GFAP+ (Fig. 3). By contrast, cells grown in medium supplemented with $2 \%$ fetal calf serum or in either $\mathrm{N} 2$ defined medium or ODM had thick, webby processes or membranous expansions and were usually $\mathrm{GC}+$ (Fig. 3).

We observed GFAP + and GC + PB cells in all of the media tested. The percentages of cells that expressed GC and GFAP were, however, remarkably different in the different media (Fig. 4). There was a consistent relationship that as the fetal calf serum content of the growth medium was decreased, the percentage of $\mathrm{GC}+$ cells increased, and the percentage of GFAP + cells decreased. The percentage of nonstained cells remained fairly constant. Similar proportions of GFAP+, GC+, and nonstained cells were seen in both N2 and ODM defined media. As was seen in earlier experiments, there was considerable variability
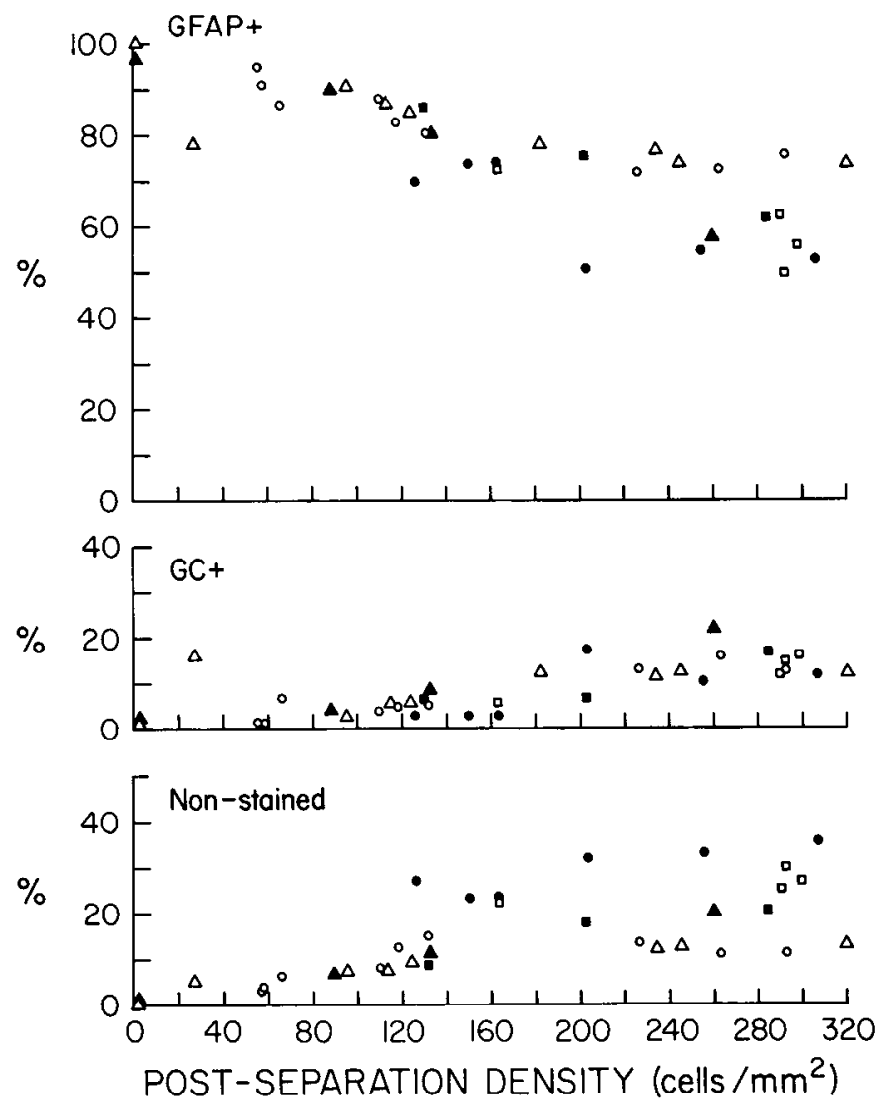

Figure 2. Expression of glial markers by PB cells plated at various densities after being shaken off bed layer polygonal astroglia, i.e., plated at various postseparation cell densities. Data are expressed in terms of the cells $/ \mathrm{mm}^{2}$ counted on coverslips following immunocytochemistry. Data from 4 experiments, each designated by a diferent symbol are shown. Each point represents the value from a single coverslip on which at least 500 cells were counted. The lowest postseparation density corresponded to $1 \mathrm{cell} / \mathrm{microscopic}$ field and the highest to $40 \mathrm{cells} / \mathrm{field}$ when a $63 \times$ objective was used for counting.

among different culture preparations; however, the trend of decreased serum yielding many GC+ cells and higher serum yielding many GFAP + cells was clear and reproducible.

There appeared to be some cell loss (10-15\%) in the defined media and in BME supplemented with $2 \%$ fetal calf serum, although this was not quantitated. A preliminary experiment using combined ${ }^{3} \mathrm{H}$-thymidine autoradiography and immunocytochemistry was carried out to determine if the PB cells were undergoing cell division. PB cells grown in BME- $20 \%$ or N2 defined medium were labeled for $4 \mathrm{hr}$ with $3 \times 10^{8} \mathrm{Ci} / \mathrm{ml}$ of ${ }^{3} \mathrm{H}$-thymidine on days 2,5 , and 9 . Some cultures were stained immediately after a $4 \mathrm{hr}$ pulse with ${ }^{3} \mathrm{H}$-thymidine, and sister cultures were stained on day 9. Slides of cultured cells were processed for autoradiography. In BME- $20 \%$, approximately $5 \%$ of the GFAP + cells radiolabeled and stained on day 2 were labeled with ${ }^{3} \mathrm{H}$-thymidine, and none of the other cell types were labeled with ${ }^{3} \mathrm{H}$-thymidine. In BME- $20 \%$, of the cells labeled on day 2 and stained on day $9,30 \%$ of the GFAP+ cells were labeled and less than $5 \%$ of any other cell types. The labeling index for all cell types in BME- $20 \%$ at the later time points was less than 5\%. In N2 defined medium, the labeling index for all cell types at all times examined was less than $5 \%$, suggesting that there was little cell proliferation in these cultures.

The data from these labeling studies combined with the ex- 
Figure 3. Immunocytochemical staining of PB cells grown in different culture media. $a$, Phase-contrast photomicrograph of $\mathrm{PB}$ cells grown in BME$20 \%$ fetal calf serum. $b$, Same field as $a$, but with optics to visualize staining with antibodies to GFAP. $c$, Same field as $a$, but stained with antibodies to GC. This staining is similar to that observed in controls. $d$, Phase-contrast photomicrograph of PB cells grown in N2 defined medium. Note the highly branched cells with thick processes. $e$, Cells immunostained for GFAP. Only one cell in this field was stained. $f$, Cells immunostained for GC. Magnification: $a-$ $c, \times 302 ; d-f, \times 192$. Scale bars: $a-c, 34$ $\mu \mathrm{m} ; d-f, 52 \mu \mathrm{m}$.
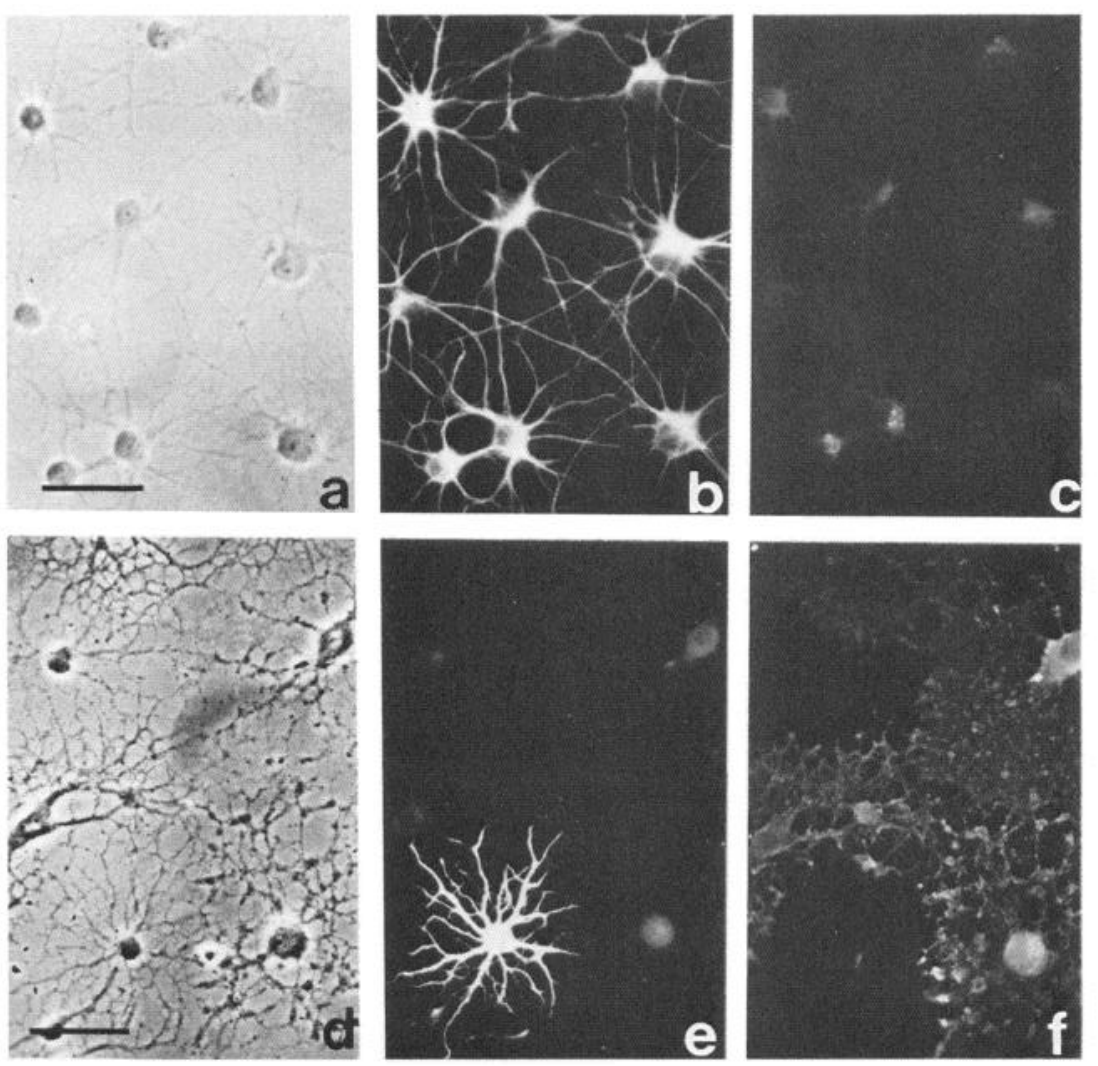

periments on the effects of culture medium on the expression of glial markers were consistent with the idea that, at least in $\mathrm{N} 2$, some of the PB cells appeared to be switching their phenotype from the expression of GFAP in serum-containing medium to GC in serum-free defined medium. The situation was more complicated in BME- $20 \%$ because of cell proliferation. We did not examine the proliferation of PB cells in ODM.

\section{Evaluation of the period of plasticity during which the type of growth media influenced $P B$ cell determination}

Experiments were carried out to determine if, in our in vitro system, there was a limited time period during which the PB cells were sensitive to the effects of variations in the type of culture medium in which they were grown. Cultures were prepared as described. All cultures were grown in BME-10\% until day 1 after separation (shaking). At this point, cultures were rinsed and fed with either BME- $20 \%$ or N2 defined medium. Subsequently, the cultures were rinsed, fed with the designated medium, and processed for immunocytochemistry. This experiment was repeated 4 times with similar results, and data from a typical experiment are shown in Figure 5.

Eighty percent or more of the PB cells that were grown in BME supplemented with $20 \%$ fetal calf serum from day 1 after shaking expressed GFAP throughout the time period examined, i.e., days 4-13 after shaking (Fig. 5, open bars). As indicated by the solid bars, $80 \%$ or more of the PB cells grown in N2 defined medium during this period expressed GC.

When cells were fed N2 on day 1 after shaking, $80 \%$ were $\mathrm{GC}+$ by day 3 . By contrast, when cells did not receive $\mathrm{N} 2$ until day 2 after being shaken, only $50 \%$ were $\mathrm{GC}+$ by day 5 (i.e., 3 $\mathrm{d}$ after receiving N2), and this group did not reach $80 \% \mathrm{GC}+$ until day 8 . When cells received N2 on day 4 , only $20 \%$ were
GC+ on day 7 , and only $30 \%$ were GC+ on day 10 . Among cells that did not receive N2 until day 7 in culture, only 10$20 \%$ were GC+ on days 10 and 13 . Only $10 \%$ of the cells fed $\mathrm{N} 2$ on day 10 and stained on day 13 were $\mathrm{GC}+$. Cultures were only stained 3 and $6 \mathrm{~d}$ after receiving $\mathrm{N} 2$, so it is possible that these cultures eventually would have reached the $80 \%$ GC expression seen in the other groups. These data suggested, however, that fewer PB cells expressed GC the longer the cells had been cultured in serum-containing medium.

To determine if cells grown in N2 would express GFAP when fed BME-20\%, one set of cultures was fed N2 on day 1 after shaking and was then switched to BME- $20 \%$ on day 4 (Fig. 5, vertical lines). These cultures were then stained on days 7 and 10. Assuming that these cultures were similar to sister wells on which staining was carried out, on day 4 approximately $80 \%$ of the cells would have been $\mathrm{GC}+$. At this point, the cultures were changed to BME- $20 \%$. On day $7,30 \%$ of the cells were $\mathrm{GC}+$, $40 \%$ were GFAP+, and $20 \%$ were nonstained. By day $10,90 \%$ of the cells were GFAP + , and only $10 \%$ were GC + . There were very few nonstained cells on day 10 .

Another set of cultures was grown in N2 from day 1 until day 10 after separation. On day 10 , these cultures were switched to BME-20\%. If these cultures were similar to sister wells that were stained, on day $10,90 \%$ of the cells were $\mathrm{GC}+$, and less than $10 \%$ were GFAP +. By day 13 (i.e., after 3 d growth in BME$20 \%), 60 \%$ were GFAP + and $40 \%$ were GC+. Thus, these cells appeared to be responsive to the influence of serum even after being cultured for $9 \mathrm{~d}$ in serum-free medium.

In summary, the data from these switching experiments suggested that within the time frame examined, there may be a window of time when cells placed in N2 are most capable of expressing GC. After PB cells were cultured in BME- $20 \%$ for 

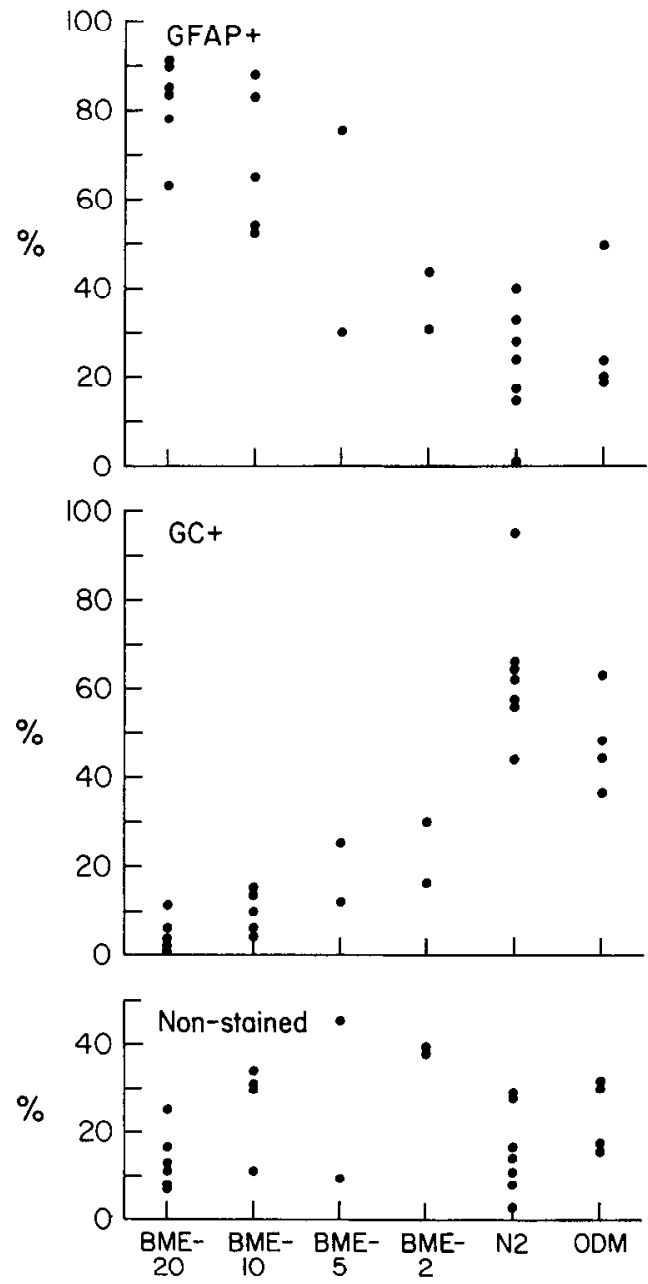

Figure 4. Quantitation of immunocytochemically stained PB cells grown in different media for 1 week. Each point is from a single experiment and is the mean value from cell counts on 3 coverslips. More than 150 cells were counted per coverslip.

longer periods, they became less sensitive or slower to respond to the influence of serum withdrawal in defined medium. When cells were cultured in $\mathrm{N} 2$ for $10 \mathrm{~d}$, when it would be expected that $90 \%$ of the cells would be GC+, and were then placed in BME- $20 \%$, only $40 \%$ of the cells were GC+ and $60 \%$ were GFAP +3 d later. This suggested that BME- $20 \%$ was still able to influence the expression of glial markers, although the effects seem to have occurred more slowly than when cells were placed in BME- $20 \%$ on day 1 . In that case, $90 \%$ of the cells were GFAP + when stained 3 d later.

\section{Observation of cells that coexpressed GFAP and GC}

The appearance of a small population of cells that were doublestained with both GFAP and GC was consistent with the idea of cells acquiring one marker before they had lost the other. The cells that expressed both GFAP and GC often had a weblike morphology (Fig. 6). These cells were usually, though not always, seen soon after cultures had been fed with a different type of growth medium.

\section{Discussion}

The data presented in this paper indicate that $\mathrm{PB}$ cells prepared by the method of McCarthy and deVellis (1980) are in a de-
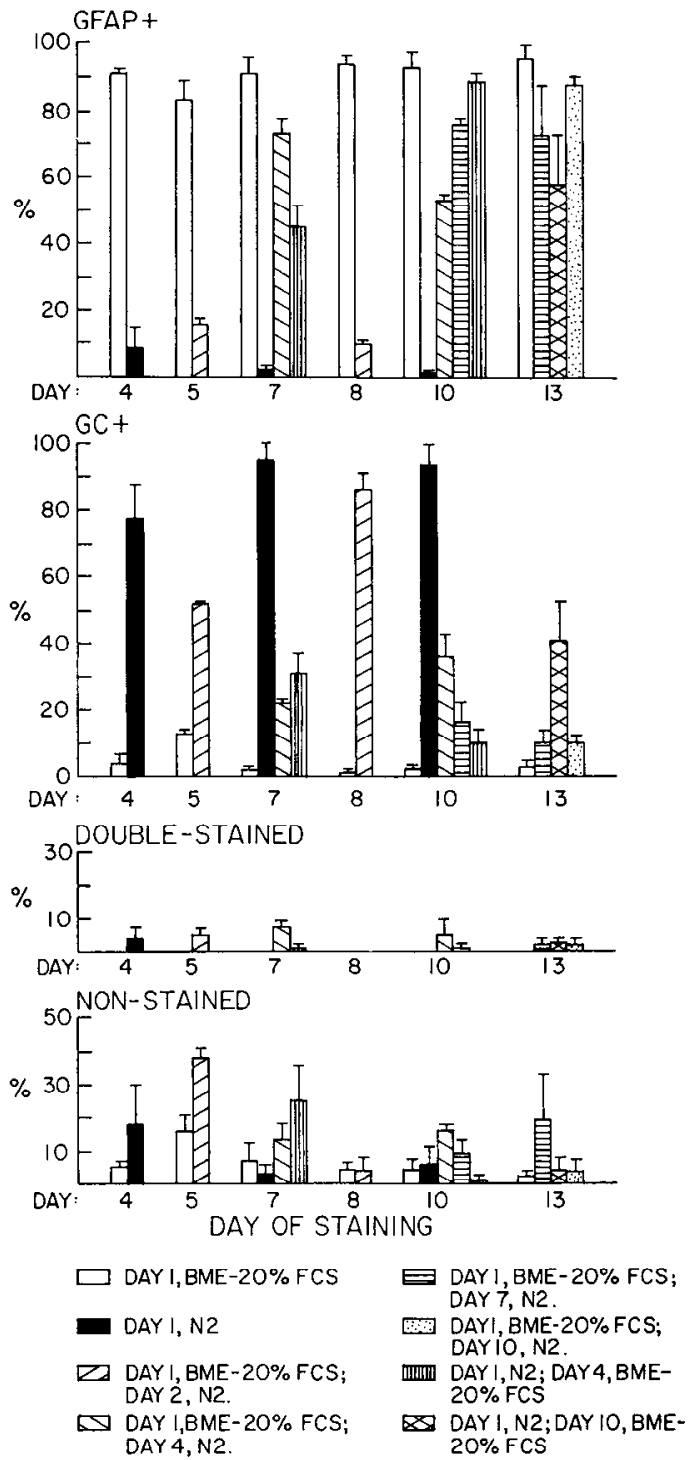

Figure 5. Glial marker expression by PB cells grown in N2 and BME$20 \%$ fetal calf serum at different times in culture. See text for details.

velopmental stage of plasticity. The determination of these cells to either an oligodendroglial or astroglial phenotype is dependent on the medium in which they are cultured. Most PB cells cultured in 10-20\% fetal calf serum expressed GFAP, while the majority of those cultured in defined medium expressed GC. There appeared to be a limited critical period during which cells could develop the oligodendroglial phenotype in response to serum withdrawal from their culture medium.

We observed no differences in the percentages of PB cells that expressed GC or GFAP in cultures prepared from either 1 or 2 $\mathrm{mm}$ pieces of cerebral cortex. This finding suggests that the entire cortex could be used in culture preparation unless one is concerned with potential regional variation in astroglia (DenisDonini et al., 1984; Barbin et al., 1986) and oligodendroglia. Our descriptions of the morphology of cells in cultures plated at different initial densities and observations on yields are similar to other descriptions of dissociated brain cell cultures (e.g., Manthorpe et al., 1979; Labourdette et al., 1980; Stieg et al., 1980; Abney et al., 1981; Pfeiffer et al., 1981; McMorris, 1983; Chiu and Goldman, 1984). 

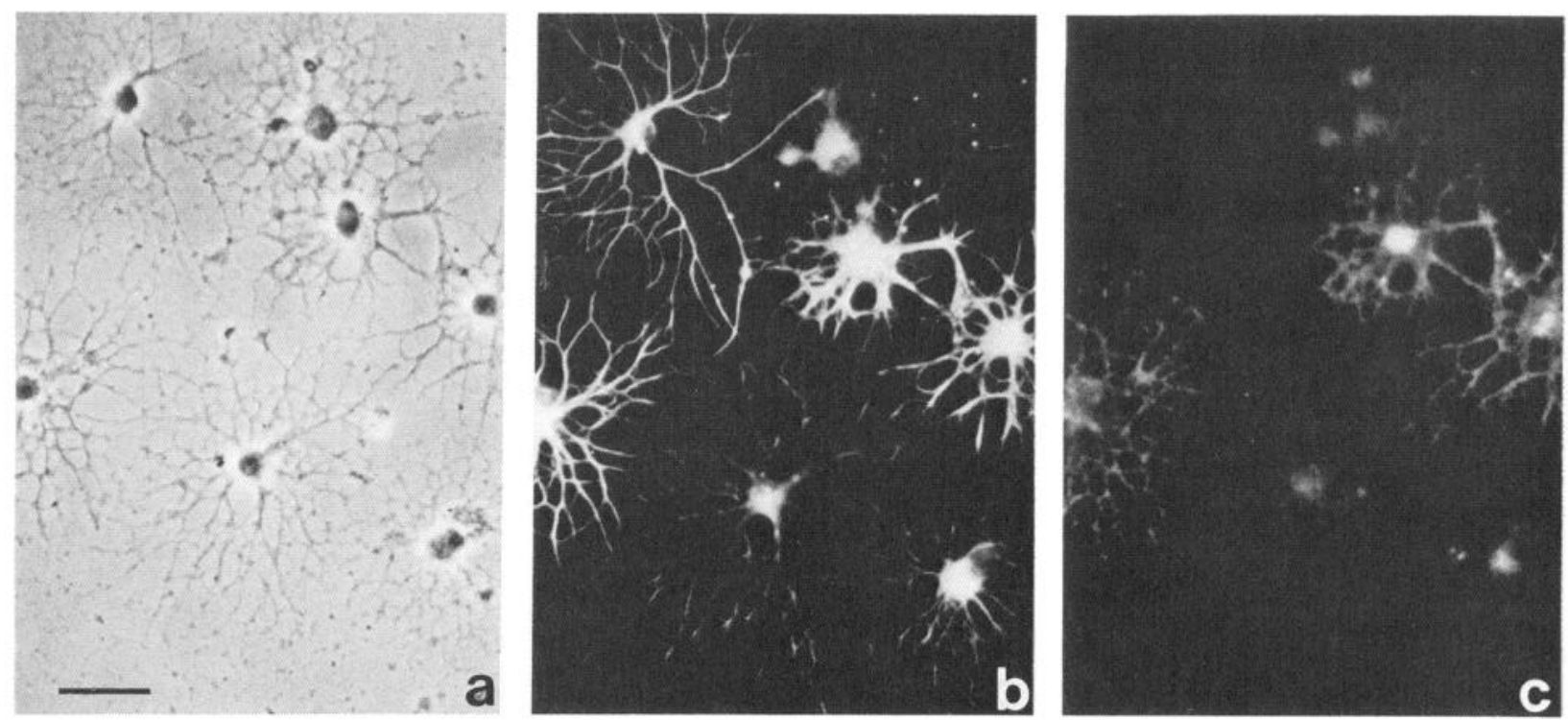

Figure 6. Double-stained (GFAP+ and GC+) PB cells. These cells were grown in N2 for 4 d. $a$, Phase-contrast photomicrograph of the same field shown in $b$ and $c$. $b$, Cells stained with anti-GFAP and rhodamine-tagged secondary antiserum. $c$, Cells stained with anti-GC and FITC-tagged secondary antiserum. At least 3 cells were double-stained. Double-stained cells typically had this weblike morphology. The cell in the upper-left corner was only GFAP.$+ \times 269$. Scale bar, $37 \mu \mathrm{m}$.

Our data on the influence of medium composition on glial cell marker expression by PB cells from cerebral cortex are consistent with other recent observations (Eccleston and Silberberg, 1984; Poduslo et al., 1984; Saneto and deVellis, 1985; Zeller et al., 1985; Dubois-Dalcq et al., 1986; Goldman et al., 1986). This description of a population of cells isolated from the cerebral cortex that could express GFAP when cultured in the presence of serum and GC when cultured in defined medium is similar to that of a cell population prepared from cultured 7 d optic nerve reported by Raff et al. (1983) and of cells in cerebellar cultures (Levi et al., 1986). The optic nerve cells and cerebellar cultures exhibited similar plasticity in their expression of glial cell markers depending on the composition of the culture medium.

Data from our preliminary ${ }^{3} \mathrm{H}$-thymidine-labeling studies combined with the information on the effects of culture medium are consistent with the idea that, at least in N2 defined medium (where there was little if any proliferation), PB cells were able to switch from expressing GFAP to expressing GC. These data strongly support our hypothesis that PB cells isolated from cerebral cortex are in a state of plasticity.

The results presented in Figure 5 strongly suggest that there was a critical time period when PB cells were most responsive to serum withdrawal from their culture medium. Raff et al. (1984) examined the reversibility of serum effects on the determination of PB cells from cultures from $7 \mathrm{~d}$ optic nerve. They observed that PB cells from cultures of optic nerve that were grown for $3 \mathrm{~d}$ or more in serum-containing medium were unable to express GC when placed in serum-free medium. These data are similar to our observations. In contrast to our data, Raff et al. (1984) found that optic nerve cells cultured in serum-free medium for longer than $2 \mathrm{~d}$ did not respond to serum-containing medium by the expression of GFAP. Possible explanations for these differences are, first, that the cells from the optic nerve differ considerably from the cells examined in our study, and second, in the optic nerve experiments, the longest time point examined on switching from serum-free to serum-containing medium was $2 \mathrm{~d}$ in serum-free followed by $2 \mathrm{~d}$ in serum-containing medium. It is possible that the cells would have developed GFAP with a longer time in culture.

The appearance of cells that were double-stained with antibodies to both GFAP and GC was consistent with the hypothesis of cells capable of switching their phenotypic expression. Cells that express features of both astroglia and oligodendroglia have been observed in a number of in vitro and in vivo systems (Raff et al., 1983; Choi and Kim, 1985; Kim et al., 1985; Temple and Raff, 1985), but the possible relevance of such cells to normal development is not yet resolved. Coexpression of these glial cell-specific antigens could result from regulation at the transcriptional or translational level so that there is active production of both GC and GFAP in the same cells. Alternatively, GC/GFAP double-staining could reflect differences in the turnover rates of GC and GFAP so that cells still express one antigen that is not actively being produced while they synthesize another.

The data presented here should help to reconcile the contradictory EM, biochemical, and immunocytochemical characterizations of PB cells prepared by the method of McCarthy and deVellis (1980). The following model is consistent with the data presented previously (McCarthy and deVellis, 1980) and in this paper. Most PB cells in unshaken, mixed cultures from cerebral cortex exhibit EM features and biochemical properties of immature oligodendroglia. PB cells shaken off of flat polygonal cells continue to express features of oligodendroglia for a short time after shaking $(48 \mathrm{hr})$. These cells are, however, in a stage of plasticity, at least in culture, and their phenotypic expression is influenced by the composition of the culture medium. PB cells continue as oligodendroglia in defined medium or convert to astroglia in serum-containing medium. Serum contains factor(s) that are stimulatory to the expression of the astroglial phenotype and/or inhibitory to the oligodendroglial phenotype. Of relevance to this model is the suggestion that since PB cells in mixed cultures exhibit features of oligodendroglia even in the presence of serum, that other cells in such cultures may serve to stabilize the oligodendroglial phenotype (Goldman et al., 1986). 
This model and our data suggest that the PB cells are not definitivcly "oligodendroglia" as originally described, but are glial cells that retain, at least for a time, some plasticity with regard to their final phenotypic expression. This model system should be useful in examining the factors that influence oligodendroglial and astroglial determination.

\section{References}

Abney, E. R., P. P. Bartlett, and M. C. Raff (1981) Astrocytes, ependymal cells and oligodendrocytes develop on schedule in dissociated cell cultures of embryonic rat brain. Dev. Biol. 83: 301-310.

Barbin, G., B. Chamak, A. Rousselet, and A. Prochiantz (1986) Biochemical heterogeneity of cultured astrocytes from different parts of the brain. Soc. Neurosci. Abstr. 12:1110.

Bignami, A., L. F. Eng, D. Dahl, and C. T. Uyeda (1972) Localization of the glial fibrillary acidic protein in astrocytes by immunofluorescence. Brain Res. 43: 429-435.

Bottenstein, J. E., and G. H. Sato (1979) Growth of a neuroblastoma cell line in serum-free supplemented medium. Proc. Natl. Acad. Sci. USA 76: 514-517.

Chiu, F. C., and J. E. Goldman (1984) Synthesis and turnover of cytoskeletal proteins in cultured astrocytes. J. Neurochem. 42: 166174.

Choi, B. H., and R. C. Kim (1985) Expression of glial fibrillary acidic protein by immature oligodendroglia and its implicaitons. J. Neuroimmunol. 8: 215-235.

Cohen, J. (1969) Statistical Power Analysis for the Behavioral Sciences, Academic, New York.

Denis-Donini, S., J. Glowinski, and A. Prochiantz (1984) Glial heterogeneity might define the three dimensional shape of mouse mesencephalic dopaminergic neurons. Nature 303: 641-643.

Dubois-Dalcq, M. E., T. N. Behar, L. Hudson, and R. A. Lazzarini (1986) Emergence of three myelin proteins in oligodendrocytes cultured without neurons. J. Cell Biol. 102; 384-392.

Eccleston, P. A., and D. H. Silberberg (1984) The differentiation of oligodendrocytes in a serum-free hormone-supplemented medium. Dev. Brain Res. 16: 1-9.

Goldman, J. E., S. S. Geier, and M. Hirano (1986) Differentiation of astrocytes and oligodendrocytes from germinal matrix cells in primary culture. J. Neurosci. 6: 52-60.

Hirayama, M., P. A. Eccleston, and D. H. Silberberg (1984) The mitotic history and radiosensitivity of developing oligodendrocytes in vitro. Dev. Biol. 104: 413-420.

Ingraham, C. A., and K. D. McCarthy (1984) Oligodendroglial cell differentiation: Effects of culture conditions. Trans. Am. Soc. Neurochem. 15: 56 .

Jacobson, M. (1978) Developmental Neurobiology, Plenum, New York.

Kim, S. U., G. Moretto, D. H. Shin, and V. M. Lec (1985) Modulation of antigenic expression in cultured adult human oligodendrocytes by derivatives of adenosine $3^{\prime}, 5^{\prime}$-cyclic monophosphate. J. Neurol. Sci. 69: 81-91.

Labourdette, G., G. Roussel, and J. L. Nussbaum (1980) Oligodendroglia content of glial cell primary cultures, from newborn rat brain hemispheres, depends on the initial plating density. Neurosci. Lett. 18: 203-209.

Levi, G., V. Gallo, and T. Ciotti (1986) Bipotential precursors of putative fibrous astrocytes and oligodendrocytes in rat cerebellar cultures express distinct surface features and "neuron-like" $\gamma$-aminobutyric acid transport. Proc. Natl. Acad. Sci. USA 83: 1504-1 508.
Manthorpe, M., R. Adler, and S. Varon (1979) Development, reactivity and GFA immunofluorescence of astroglia-containing monolayer cultures from rat cerebrum. J. Neurocytol. 8: 605-621.

McCarthy, K. D., and J. deVellis (1978) Alpha-adrenergic receptor modulation of $\beta$-adrenergic, adenosine and prostaglandin $E 1$ increased adenosine $3^{\prime}, 5^{\prime}$-cyclic monophosphate levels in primary cultures of glia. J. Cyclic Nucleotide Res. 4: 15-26.

McCarthy, K. D., and J. deVcllis (1980) Preparation of separate astroglial and oligodendroglial cell cultures from rat cerebral tissue. J. Cell Biol. 85: 890-902.

McCarthy, K. D., J. Prime, T. Harmon, and R. P. Pollenz (1985) Receptor-mediated phosphorylation of astroglial intermediate filament proteins in cultured astroglia. J. Neurochem. 44: 723-730.

McMorris, F. A. (1983) Cyclic AMP induction of the myelin enzyme $2^{\prime}, 3^{\prime}$-cyclic nucleotide 3 '-phosphohydrolase in rat oligodendrocytes. J. Neurochem. 41: 506-515.

Meyer, S. A., C. A. Ingraham, and K. D. McCarthy (1986) Intermediate filament proteins of cultured process-bearing and polygonal astroglia. Fed. Proc. 45: 1066.

Norton, W. T., and L. A. Autilio (1966) The lipid composition of purified bovine brain myelin. J. Neurochem. 13: 213-222.

O'Farrell, P. H. (1975) High resolution two-dimensional electrophoresis of proteins. J. Biol. Chem. 250: 4007-4021.

Pfeiffer, S. E., E. Barbarese, and S. Bhat (1981) Non-coordinate regulation of myelinogenic parameters in primary cultures of dissociated fetal rat brain. J. Neurosci. Res. 6: 369-380.

Poduslo, S. E., K. Miller, R. Curbeam, and P. Reier (1984) Purification and characterization of cultures of oligodendroglia from rat brain. Soc. Neurosci. Abstr. 10: 765 .

Raff, M. C., R. Mirsky, K. L. Fields, R. P. Lisak, S. H. Dorfman, D. H. Silberberg, N. A. Gregson, S. Leibowitz, and M. C. Kennedy (1978) Galactocerebroside is a specific cell-surface marker for oligodendrocytes in culture. Nature 274: 813-816.

Raff, M. C., R. H. Miller, and M. Noble (1983) A glial progenitor cell that develops in vitro into an astrocyte or an oligodendrocyte depending on culture medium. Nature 303: 390-396.

Raff, M. C., B. P. Williams, and R. H. Miller (1984) The in vitro differentiation of a bipotential glial progenitor cell. EMBO J. 3: $1857-$ 1864.

Ranscht, B., P. A. Clapshaw, J. Price, M. Noble, and W. Seifert (1982) Development of oligodendrocytes and Schwann cells studied with a monoclonal antibody against galactocerebroside. Proc. Natl. Acad. Sci. USA 79: 2709-2713.

Saneto, R. P., and J. deVellis (1985) Characterization of cultured rat oligodendrocytes proliferating in a serum-free, chemically defined medium. Proc. Natl. Acad. Sci. USA 82: 3509-3513.

Stieg, P. E., H. K. Kimelberg, J. E. Mazurkiewicz, and G. A. Banker (1980) Distribution of glial fibrillary acidic protein and fibronectin in primary astroglial cultures from rat brain. Brain Res. 199: 493500 .

Temple, S., and M. C. Raff (1985) Differentiation of a bipotential glial cell in single cell microculture. Nature 313: 223-225.

Trimmer, P. A., T. Evans, M. M. Smith, T. K. Harden, and K. D. McCarthy (1984) Combination of immunocytochemistry and radioligand receptor assay to identify $\beta$-adrenergic receptor subtypes on astroglia in vitro. J. Neurosci. 4: 1598-1606.

Zeller, N. K., T. N. Behar, M. E. Dubois-Dalcq, and R. A. Lazzarini (1985) The timely expression of myelin basic protein gene in cultured rat brain oligodendrocytes is independent of continuous neuronal influences. J. Neurosci. 5: 2955-2962. 